\title{
Conservation of an Overlooked Resource - Volunteers
}

\author{
Partnering with volunteers can accomplish great things \\ for natural resources.
}

\section{By Randy Russell and Earle Kirkbride}

$\mathrm{I}$ $f$ conservation is defined as a "wise use of resources," then many rangeland managers fall short in their conservation efforts. Volunteers are a valuable rangeland management resource that is to often overlooked.

In December 1993 Rangelands published an article about the use of volunteers. The 1993 article discussed using individual volunteers to accomplish forest and range related tasks. These tasks included participating in cattle drives, building new fence and fixing old fence, and constructing spring developments. One of the authors of that 1993 article Earle Kirkbride - came on as a volunteer on the Pine Valley District of the Dixie National Forest located in southern Utah near St. George, Utah in 2003.

The author of the 1993 article is now in his thirteenth summer of volunteering - most of them with Rangeland Management Specialists on various National Forests in five western states. He is collaborating on this article about the use of volunteer groups and how they can help range managers accomplish goals that might otherwise be unachievable as well as produce good will for the land agency using the volunteer labor force.

The Range Program of the Pine Valley District of the Dixie National Forest has used about six groups of volunteers to accomplish two major labor-intensive projects per year for the past several years. These projects have ranged from tasks that required the efforts of only a few people such as fabricating and installing metal escape ramps in livestock water troughs for wildlife to large ones such as constructing four miles of riparian fence that involved 60 people over a period of ten days. We wrote this paper to explain the benefits and requirements of using volunteers and hopefully others successfully use this valuable resource.

\section{Where are these Volunteers?}

Potential volunteer groups and individuals are around every Forest Service district and probably around every other land management agency office. They are the people who in some way or another use the natural resource or wish to see it properly cared for. Wilderness managers have long been forming alliances with groups such as the Back Country Horsemen to build or maintain trails. Range managers can do the same thing.

For example, there are many groups these days interested in improving habitat and forage conditions for wildlife. There are groups interested in helping protect endangered species - plant as well as animal. There also "partner" programs where other agencies or groups have formal relationships to sup-

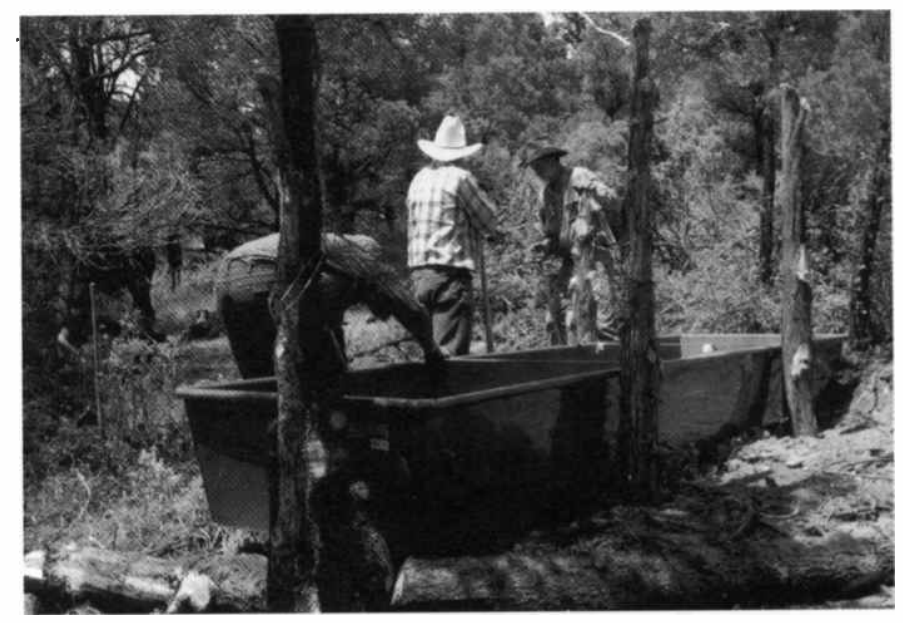

Volunteers installing watering trough in a remote area. Trough was helicoptered to site. Photo by Frank Jones. 
port each other. One of these - the "Dedicated Hunter" program (which is discussed in detail below) - has been particularly useful to the Pine Valley District.

If a range manager really gets motivated to find these groups, they might even discover that some of the people who regularly object to agency actions could be recruited to remedy problems that are bothering both them and the range manager. Maybe that is wishful thinking, but in some cases it has been possible.

\section{What's in it for the Volunteers?}

That is a question the range manager must ask from the viewpoint of the group being recruited. The Dedicated Hunter Program has a clear answer to that question. In Utah, the Division of Wildlife Resources has partnered with the Forest Service. A hunter can earn hours toward completing a requirement for obtaining a special deer tag. Sometimes a group of hunters will combine efforts on a project, and sometimes they bring in heavy equipment to accomplish a project. An example of this kind of project accomplished through the Dedicated Hunter program is the construction or cleaning of a water collection pond for wildlife.

On another occasion, 90 hunters through the Dedicated Hunter program thinned over 800 acres of pinion Juniper that had grown up in an area that had been "chained" 20 or so years ago. ("Chaining" was a practice of dragging heavy anchor chains attached to two bulldozers through areas to clear unwanted vegetation). This is an example of a project that would have been difficult to accomplish with Forest Service employees given the limited resources currently available.

Less formal than the Dedicated Hunter Program is the relationship the range program of the Pine Valley District has with the Escalante Valley Wildlife Association. This is a group of local rural people interested in enhancing the environment primarily for wildlife and secondarily for cattle. They approached the District with their offer of help and have completed numerous spring developments and associated fencing, water catchments, and sign installation, along with litter clean up around a prominent reservoir.

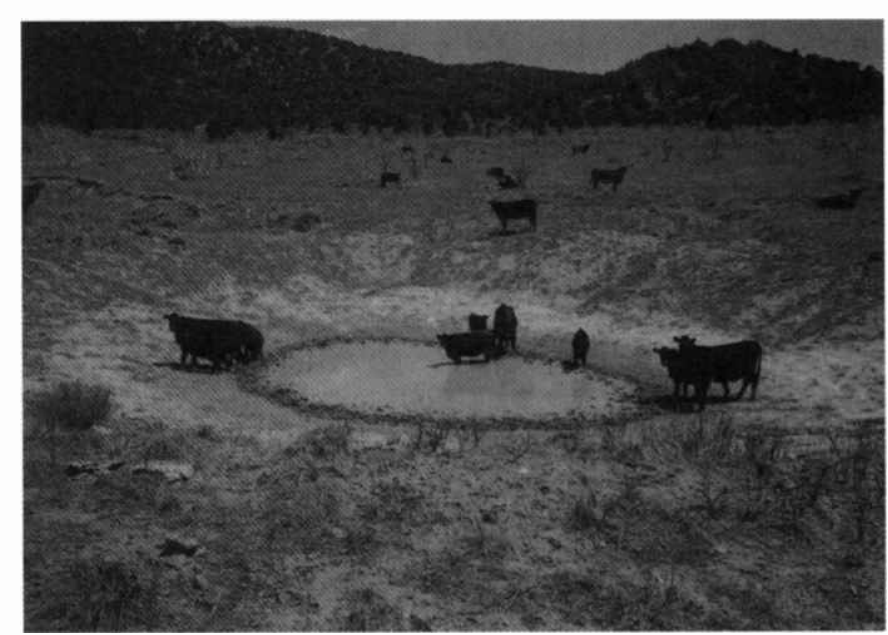

Water catchment area created with help of volunteers in Dedicated Huner program on Pine Valley District of Dixie National Forest. To seal bottom, district employees lined pond with blue clay to retain water (lighter color). Photo by Frank Jones.

The local chapter of the Rocky Mountain Elk Foundation too has accomplished range improvements to benefit deer. Among the projects they have completed is the construction of a trick tank that collects precipitation in a storage tank and distributes it to a water trough. Currently there is discussion with this group to fund a prescribed burn of 10,000 or more acres to enhance vegetation diversity.

The National Mustang Association is concerned about a gate being left open periodically between wild horse range and a cattle allotment. The group may provide materials to install a cattle guard to overcome the problem. If that arrangement can be made, it may be possible to partner with the Bureau

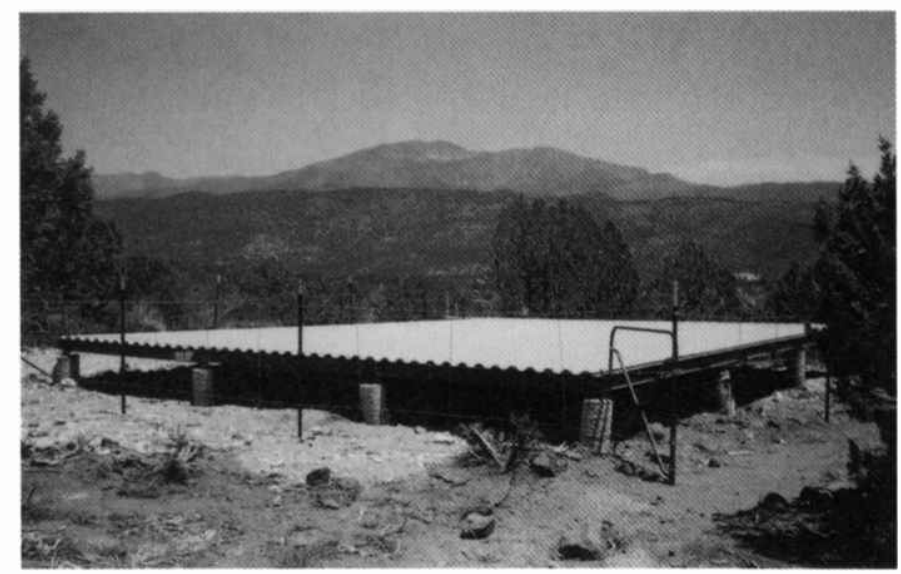

Guzzler installed by Enterprise Wildlife Association on Pine Valley District of Dixie Forest. Photo by Frank Jones. 
of Land Management and the Forest and perhaps additional groups to get the cattle guard installed.

\section{Our Volunteers' Accomplishments}

In addition to the large projects mentioned above, the range program on the Pine Valley District has used individual volunteers and small groups to accomplish the following projects:

$\rightarrow$ Seeding six acres with grass seed

$\rightarrow$ Hanging gates

$\rightarrow$ Daily feeding of saddle horses at a remote site

$\rightarrow$ Construction of a fishing platform for physically challenged people

$\rightarrow$ Eradicating 11 acres of Salt Cedar and Scotch Thistle

$\rightarrow$ Picking up trash at recreation reservoirs

$\rightarrow$ Checking fences around remote grazing allotments

$\rightarrow$ Spraying noxious weeds

$\rightarrow$ Building riparian fences in remote areas

$\rightarrow$ Monitoring wild horse herds and assisting with gathers

$\rightarrow$ Installing identification and directional signs

$\rightarrow$ Developing springs and installing troughs

$\rightarrow$ Documentation of projects and professional writing

In one instance, ranchers rode horses into a remote site to assemble and install a watering tank after the parts were delivered by helicopter.

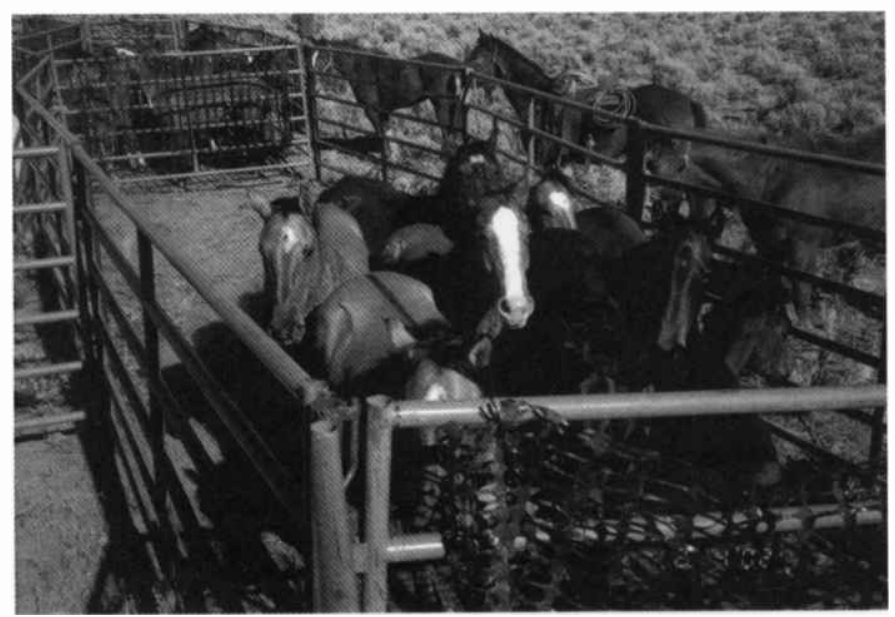

Some of the 80 wild horses gathered and removed with help of volunteers on Pine Valley District of Dixie National Forest. Photo by Randy Russell.

\section{Requirements for Success in Volunteer Use}

Even the most dedicated range manager is destined to fail in trying to use volunteers - either individuals or groups - unless they have the full support of their manager. In the Forest Service that means the support of the District Ranger, and at least the Forest Supervisor. Ideally, more than just lip service would exist at the Region level. That kind of support has been present on the Pinedale Ranger District where volunteers are used extensively in nearly all parts of the organization.

Likewise, support in the form of vehicles and some funds have been available. It is also important that all members of offices be supportive of the use of volunteers. A negative attitude toward volunteers expressed by anyone in the agency can destroy enthusiasm and even possibly discourage volunteers from again coming forward. Agency support personnel and the range manager must also be willing to deal with the mechanics and the paperwork necessary to use volunteers. These details take time, and the range manager must be reconciled to the fact that they must invest time and effort to get results.

Finally, the importance of expressing appreciation to volunteers cannot be overemphasized. A regular "Thank You" and more formal recognitions are vital. The mass-produced certificate or small pin or a cap may sound trite, but the importance of such formal recognition should not be overlooked. The volunteer may dismiss it as unnecessary, but if it isn't presented it is missed, and when it is received it is shown to friends and family who may appreciate the agency more.

Publicity about opportunities and the agency's attitude toward the public in all its forms is vital. Only if the agency is well-regarded will individuals and groups be interested in helping a range manager. If they are seen as approachable and someone with the same interests as the potential volunteer it will be possible to generate interest in volunteering.

In short, the range manager and their supervisors must be seen as not just enforcers of big government rules but as individuals who are dedicated professionals trying their best to preserve, protect, and enhance natural resources for the benefit of all citizens. If a range manager is able to accomplish 
this, they may even be able to generate support from some of the people who often oppose agency actions of policies.

Patience and willingness to deal with unforeseen problems is a necessary characteristic of a range manager attempting to use volunteers. There will be problems. That can be counted on. Many times, it might be very tempting to simply throw up one's hands and do only what can be accomplished with limited paid employees. Successfully coping with these problems can give a sense of accomplishment to a manager, and certainly is good training for higher level positions. (The use of volunteers - either individuals or groups - might be more widespread if there were more tangible rewards for the manager willing to put forth the effort to accomplish more through the use of volunteers).

\section{The Potential}

A range manager willing to put forth the effort to promote and operate a meaningful volunteer program can accomplish a great deal for their agency. It is possible to accomplish 15-20 projects in a year - projects that probably would not otherwise be accomplished.

Also, maybe even more important, all the volunteers will probably have a much more favorable impression of the agency than they did before becom- ing involved. Each of those individuals, in turn, usually is a center of influence for from six to sixty other individuals. Often such individuals exude a certain amount of pride of accomplishment that is not only good for them but may also encourage others to volunteer.

\section{Getting Started}

Agencies and individual managers who think they could benefit from more extensive use of volunteers should "brainstorm" the subject - identify areas where volunteers might help. Then they should try to identify some groups and individuals who might see a benefit to their members in tackling some agency project and start publicizing the things that need to be done.

When volunteers accomplish something, the rest of the community should be made aware of it. Publicity is apt to bring in more interested people, and range managers may see even more of their projects get accomplished.

About the Authors: Randy Russell is the Rangeland Management Specialist on the Pine Valley Ranger District of the Dixie National Forest in St. George, Utah. Earle Kirkbride in 2003 started his $13^{\text {th }}$ summer as a volunteer with the Forest Service. He has volunteered five summers in Montana, two in Colorado, three in Wyoming, two in Oregon and one in Utah. 